\title{
Clinicoimmunopathologic findings in Atlantic bottlenose dolphins Tursiops truncatus with positive cetacean morbillivirus antibody titers
}

\author{
Gregory D. Bossart ${ }^{1,2, *}$, Tracy A. Romano ${ }^{3}$, Margie M. Peden-Adams ${ }^{4}$, \\ Adam Schaefer ${ }^{2}$, Stephen McCulloch ${ }^{2}$, Juli D. Goldstein ${ }^{2}$, Charles D. Rice ${ }^{5}$, \\ Jeremiah T. Saliki ${ }^{6}$, Patricia A. Fair ${ }^{7}$, John S. Reif ${ }^{8}$ \\ ${ }^{1}$ Georgia Aquarium, Atlanta, Georgia 30313, USA \\ ${ }^{2}$ Harbor Branch Oceanographic Institute at Florida Atlantic University, Ft. Pierce, Florida 34946, USA \\ ${ }^{3}$ The Mystic Aquarium, a division of Sea Research Foundation, Mystic, Connecticut 06355, USA \\ ${ }^{4}$ Harry Reid Center for Environmental Studies, University of Nevada Las Vegas, Las Vegas, Nevada 89154, USA \\ ${ }^{5}$ Department of Biological Sciences, Graduate Program in Environmental Toxicology, Clemson University, Clemson, \\ South Carolina 29634, USA \\ ${ }^{6}$ Athens Veterinary Diagnostic Laboratory, University of Georgia, Athens, Georgia 30602, USA \\ ${ }^{7}$ National Oceanic and Atmospheric Administration, National Ocean Service, Center for Coastal Environmental Health and \\ Biomolecular Research, Charleston, South Carolina 29412, USA \\ ${ }^{8}$ Department of Environmental and Radiological Health Sciences, College of Veterinary Medicine and Biomedical Sciences, \\ Colorado State University, Fort Collins, Colorado 80523, USA
}

\begin{abstract}
Sera from free-ranging Atlantic bottlenose dolphins Tursiops truncatus inhabiting the Indian River Lagoon (IRL), Florida were tested for antibodies to cetacean morbilliviruses from 2003 to 2007 as part of a multidisciplinary study of individual and population health. A suite of clinicoimmunopathologic variables were evaluated in morbillivirus-seropositive dolphins $(\mathrm{n}=14)$ and seronegative healthy dolphins $(n=49)$. Several important differences were found. Serum alkaline phosphatase, creatine phosphokinase, chloride, albumin and albumin/globulin ratios were significantly lower in seropositive dolphins. Innate immunity appeared to be upregulated with significant increases in lysozyme concentration and marginally significant increases in monocytic phagocytosis. Adaptive immunity was also impacted in dolphins with positive morbillivirus antibody titers. Mitogen-induced T lymphocyte proliferation responses were significantly reduced in dolphins with positive morbillivirus antibody titers, and marginally significant decreases were found for absolute numbers of CD4+ lymphocytes. The findings suggest impairment of cell-mediated adaptive immunity, similar to the immunologic pattern reported with acute morbillivirus infection in other species. In contrast, dolphins with positive morbillivirus antibody titers appeared to have at least a partially upregulated humoral immune response with significantly higher levels of gamma globulins than healthy dolphins, which may represent an antibody response to morbillivirus infection or other pathogens. These data suggest that subclinical dolphin morbillivirus infection in IRL dolphins may produce clinicoimmunopathologic perturbations that impact overall health.
\end{abstract}

KEY WORDS: Bottlenose dolphin - Viral disease - Cetacean morbillivirus - Seroepidemiology · Clinical pathology $\cdot$ Immunology

Resale or republication not permitted without written consent of the publisher

\section{INTRODUCTION}

Historically, members of the genus Morbillivirus within the family Paramyxoviridae include measles virus (MV) of primates, canine distemper virus (CDV) of carnivores and rinderpest virus (RPV) and pestedes-petits-ruminants virus (PPRV) of cloven-hoofed animals. More recently, phocine distemper virus 
(PDV) and cetacean morbilliviruses (dolphin morbillivirus [DMV] and porpoise morbillivirus [PMV]) have emerged and dramatically impacted the health and population status of various marine mammal species worldwide (Kennedy 1998, Di Guardo et al. 2005, Di Guardo 2008, Van Bressem et al. 2009). The DMV and PMV viruses appear to be closely related strains of a cetacean morbillivirus (CMV) from a genomic and antigenic standpoint (BlixenkroneMøller et al. 1994, Kennedy 1998, Di Guardo et al. 2005), distinct from PDV and CDV and more closely related to the ruminant morbilliviruses and measles virus (Barrett et al. 1993, Visser et al. 1993).

In domestic animals and primates, morbilliviruses produce a seemingly paradoxical interaction with the immune system. Morbilliviruses are lymphotrophic and induce multisystemic infections in their highly susceptible natural hosts, causing disease with high morbidity and mortality. In these cases, the pathogenesis of morbillivirus infections shares common features, including transient profound immune suppression which may lead to secondary viral and bacterial infections, and associated clinicoimmunopathologic abnormalities (von Messling et al. 2003, Heaney et al. 2005, Yanagi et al. 2006, Nielsen et al. 2009). Another attribute of morbillivirus infections is the induction of an efficient and often lifelong immunity in hosts that eventually survive and appear to clear the virus (Appel et al. 1982, Griffin 2007).

The pathogenesis and subsequent clinicoimmunologic responses of morbillivirus infection in dolphins are unknown. However, we recently reported the detection of antibodies against DMV and PMV in free-ranging Atlantic bottlenose dolphins Tursiops truncatus from the Indian River Lagoon (IRL), Florida, as part of a $5 \mathrm{yr}$ multidisciplinary health and risk assessment study of individual and population dolphin health (Bossart et al. 2010). Among dolphins captured between 2003 and 2007, positive fluctuating morbillivirus titers and seroconversion were found in IRL dolphins in the absence of a morbillivirus epizootic. In particular, evidence of CMV infection during the post 1987-1988 morbillivirus epizootic period was found with a $10 \%$ seroprevalence among IRL dolphins born after 1988. Antibody was detected in 8 to $13 \mathrm{yr}$ old IRL dolphins at the time of capture, indicating that morbillivirus transmission and infections were occurring in the absence of widespread mortality. The pattern of morbillivirus seroprevalence in younger animals, seroconversions and fluctuating antibody titers combined with absence of typical morbillivirus pathologic lesions in stranded IRL bottlenose dolphins during the same time period supported the hypothesis that subclinical morbillivirus infections occur in this population. However, unanswered questions regarding the pathogenesis of CMV infection remain, including the clinicoimmunologic effects of subclinical infection and the potential secondary impacts these changes may have on overall dolphin health. The purpose of this report is to evaluate the clinicoimmunopathologic findings in IRL dolphins with positive antibody titers to CMV.

\section{MATERIALS AND METHODS}

\section{Free-ranging dolphins}

The free-ranging Atlantic bottlenose dolphin (Tursiops truncatus) Health and Risk Assessment (HERA) project was initiated as a multidisciplinary, integrated collaborative effort in 2003 to assess individual and population health in 2 southeast coastal regions of the USA: Charleston, South Carolina, and the IRL (Bossart et al. 2006). In part, the goals of the project are to develop standardized tools for health and risk assessment, and to explore associations between health status and environmental stressors. As an apex predator, bottlenose dolphins serve as a sentinel species for monitoring the health of the environment and may provide valuable information for evaluating the relationship between exposure to biological and chemical agents and adverse health effects for these populations (Bossart 2011).

The IRL is a shallow-water ecosystem that comprises $40 \%$ of Florida's central east coast. The lagoon is an aggregate of 3 estuarine water bodies: the Indian and Banana Rivers and the Mosquito Lagoon that extends $250 \mathrm{~km}$ from Ponce De Leon Inlet in the north to Jupiter Inlet in the south. Ten years of dolphin photo-identification data indicate that IRL dolphins have strong site fidelity to the estuary and regions within it (Mazzoil et al. 2008).

Dolphins were captured in the IRL in June each year from 2003 to 2007. Sampling was conducted in specific areas within each site based on population abundance estimates obtained from photo-identification surveys (Mazzoil et al. 2008). Standard operating protocols and techniques used for capture, sample collection and release of dolphins are described in detail elsewhere (Fair et al. 2006). Health status was determined by a panel of marine mammal veterinarians as previously described and classified as clinically healthy, possibly diseased or definitely diseased (Reif 
et al. 2008). Health status was based on physical and ultrasound examinations, hematology, serum chemistry, gastric, blowhole and fecal cytology, urinalysis, and microbiologic evaluation of blowhole and rectal contents. Age was estimated by counting post-natal dentine layers in an extracted tooth (Hohn et al. 1989). All methods used in HERA for capture and blood collection were approved under National Marine Fisheries Service Scientific Research Permit No. 998-1678 issued to G. Bossart and by the Harbor Branch Oceanographic Institutional Animal Care and Use Committee.

\section{Blood collection}

Blood samples were drawn from the periarterial venous rete in the flukes (Goldstein et al. 2006), generally within the first 15 min of capture, with a 19-gauge, $1.9 \mathrm{~cm}$ butterfly catheter (Becton Dickinson). Serum was collected in $10 \mathrm{ml}$ separator vacutainer tubes (Becton Dickinson), placed in a cooler for 20 to $40 \mathrm{~min}$, and centrifuged for $15 \mathrm{~min}$ at $1200 \mathrm{rpm}(350 \times g)$. Samples for hematology and immunology were collected in a vacutainer tube with ethylene diamine tetraacetic acid (EDTA) or sodium heparin as an anticoagulant, respectively (Becton Dickinson). Samples for hematology, serum chemistry, and serum protein electrophoresis analyses were stored in an insulated cooler and shipped overnight to the Cornell University Veterinary Diagnostic Laboratory in Ithaca, New York, USA. Samples for immune assays (heparinized whole blood or serum as required) were stored in an insulated cooler and shipped overnight to Mystic Aquarium, a division of Sea Research Foundation, Mystic, Connecticut, USA and the NOAA Ocean Service, Charleston, South Carolina, USA for analysis.

\section{Hematology, serum chemistry, and serum protein electrophoresis}

For the complete blood count, relative leukocyte determinations were performed by microscopic examination of modified Wright-stained blood smears (Bayer Healthcare). A microhematocrit tube was centrifuged for $5 \mathrm{~min}$ at $11700 \mathrm{rpm}(28977 \times g)$, and the manual hematocrit was interpreted by visual inspection against a standard calibration. Automated hemoglobin, red blood cell count, mean corpuscular platelet volume (MCV), mean corpuscular hemoglobin $(\mathrm{MCH}), \mathrm{MCH}$ concentration
(MCHC), white blood cell count (WBC), and total platelets were determined by an automated analyzer (Bayer ADVIA 120, Bayer Diagnostics). The concentrations of serum chemistry analytes were determined with an automated analyzer (Hitachi 917, Roche) and included analyses for sodium, potassium, chloride, bicarbonate, anion gap, blood urea nitrogen (BUN), creatinine, uric acid, calcium, phosphorus, magnesium, glucose, total direct and indirect bilirubin, cholesterol, triglycerides, iron, and fibrinogen. Enzyme activity was determined for alanine aminotransferase (ALT), alkaline phosphatase, aspartate aminotransferase (AST), creatine phosphokinase (CPK), gamma-glutamyltransferase (GGT), lactate dehydrogenase (LDH), amylase, and lipase. Fibrinogen concentration was determined by the method of Schalm using heat precipitation. Serum protein electrophoresis was done on an automated analyzer (Rapid Electrophoresis, Helena Laboratories) as previously described (Goldstein et al. 2006). Hemolyzed or lipemic samples were not included.

\section{Morbillivirus serum neutralization test}

The serum neutralization test (SNT) was performed using the Belfast strain of dolphin morbillivirus (DMV) and porpoise morbillivirus (PMV) (provided by Dr. Seamus Kennedy, Belfast, UK, through Dr. Padraig Duignan) at the Athens Veterinary Diagnostic Laboratory University of Georgia in Athens, Georgia, USA. Virus was grown in Vero cells and the test was performed as previously described (Saliki \& Lehenbauer 2001). Briefly, serial 2 -fold dilutions of heat-inactivated sera were made in duplicate columns of 96-well plates using Dulbecco's minimum essential medium (DMEM), starting at a 1:2 dilution. An equal volume $(25 \mu \mathrm{l})$ of virus containing about $100 \mathrm{TCID}_{50}$ was added. Addition of virus yielded a final starting dilution of 1:4. The virus-serum mixtures were incubated at $37^{\circ} \mathrm{C}$ for $1 \mathrm{~h}$ in $5 \% \mathrm{CO}_{2}$ and a Vero cell suspension (150 $\mu \mathrm{l}$ containing $10^{4}$ cells per well) was added to the plates. The plates were incubated at $37^{\circ} \mathrm{C}$ in $5 \%$ $\mathrm{CO}_{2}$ for $4 \mathrm{~d}$. The test was read by examining cell monolayers under an inverted microscope for virusspecific cytopathic effects (CPE). Antibody titers were expressed as the reciprocal of the highest dilution of serum that completely neutralized CPE in duplicate. Titers $\geq 8$ were considered positive for the presence of morbillivirus neutralizing antibody in the serum (Bossart et al. 2010). 


\section{Immune assays}

The methods used for immune assays and the sources of chemicals, reagents and antibodies have been described previously (Bossart et al. 2008, Reif et al. 2009).

For assessment of proliferation, natural killer (NK) cell activity, superoxide production, immunophenotyping and proliferation, peripheral blood leukocytes (PBLs) were isolated by a slow spin technique within $36 \mathrm{~h}$ of blood collection as previously described (Keller et al. 2006) with minor modifications, counted and assessed for viability, and subsequently diluted as described for each endpoint.

\section{Immunophenotyping}

Lymphocyte subsets were labeled and analyzed according to methods described previously (Romano et al. 2004, Bossart et al. 2008, Reif et al. 2009). Briefly, $1 \times 10^{6}$ cells $\mathrm{ml}^{-1}$ were labeled with $50 \mu \mathrm{l}$ of monoclonal supernatant for $30 \mathrm{~min}$ at $4^{\circ} \mathrm{C}$ followed by fluorescein isothiocyanate-conjugated affinitypurified goat anti-mouse $\mathrm{F}(\mathrm{ab})$ ' 2 IgG for $30 \mathrm{~min}$ at $4^{\circ} \mathrm{C}$ in the dark. Cells were resuspended in $500 \mu \mathrm{l}$ of $1 \%$ paraformaldehyde for analysis by flow cytometry and analyzed on an LSR flow cytometer (BD Biosciences). A total of 10000 lymphocyte gated events were analyzed by histogram statistics.

\section{Phagocytosis}

The percent phagocytosis for phagocytic cell types (i.e. granulocytes and monocytes) was determined using a modification of the technique previously described (Lehmann et al. 2000, Flaminio et al. 2002, Bossart et al. 2008, Reif et al. 2009). Briefly, cells were incubated with $10 \mu \mathrm{l}$ of $2.1 \times 10^{9}$ units $\mathrm{ml}^{-1}$ heat-killed Staphylococcus aureus previously labeled with $100 \mu \mathrm{g} \mathrm{ml} \mathrm{m}^{-1}$ of propidium iodide at a 25:1 bacteria:cell ratio in a shaking $37^{\circ} \mathrm{C}$ water bath (100 rpm) for 0 and $75 \mathrm{~min}$. The experiment was stopped by adding $10 \mu \mathrm{l}$ of $1 \mathrm{mM}$ N-ethylmaleimide (NEM) to each tube and red blood cells were lysed by the addition of $1 \mathrm{ml}$ of lysis buffer (0.01 M Tris, $0.001 \mathrm{M}$ EDTA, $0.17 \mathrm{M} \mathrm{NH}_{4} \mathrm{Cl}, \mathrm{pH}=7.4$ ). Cells were resuspended in $250 \mu \mathrm{l}$ of $1 \%$ cold paraformaldehyde, $\mathrm{pH} 7.4$, and analyzed on an LSR flow cytometer (BD Biosciences). A total of 100000 gated cells (granulocytes and monocytes) were analyzed by histogram statistics.

\section{Lysozyme activity}

Lysozyme activity, another measure of innate immunity, was assessed using a slightly modified standard turbidity assay (Demers \& Bayne 1997, Keller et al. 2006). A solution of Micrococcus lysodeikticus was prepared fresh daily by dissolving $50 \mathrm{mg}$ of the lyophilized cells in $100 \mathrm{ml} 0.1 \mathrm{M}$ phosphate buffer (pH 5.9). Hen egg lysozyme (HEL; Sigma) was serially diluted in phosphate buffer to produce a standard curve of $40,20,10,5,2.5,1.25,0.6,0.3$, and $0 \mu \mathrm{g}$ $\mu^{-1}$. Aliquots of each concentration (25 $\mu \mathrm{l}$ per well) were added to a 96-well plate in triplicate along with $25 \mu \mathrm{l}$ of test plasma in quadruplicate. M. lysodeikticus (50 mg of cells in $100 \mathrm{ml} 0.1 \mathrm{M}$ phosphate buffer, $\mathrm{pH}$ 5.9) was added to 3 sample wells and to each of the standard wells at $175 \mu \mathrm{l}$ per well, while the fourth well served as a blank containing only phosphate buffer. Plates were assessed for absorbance at 450 nm with a spectrophotometer (SpectraCount, Packard) immediately (T0) and again after $5 \mathrm{~min}$ (T5). Absorbance unit values were converted to HEL concentration $\left(\mu \mathrm{g} \mathrm{ll}^{-1}\right)$ via linear regression of the standard curve.

\section{Mitogen-induced lymphocyte proliferation (LP)}

The LP response was measured using methods optimized previously (Peden-Adams \& Romano 2005). Briefly, isolated viable PBLs $\left(1 \times 10^{5}\right.$ cells per well $)$ were incubated in 96-well plates with $2.5 \mu \mathrm{g} \mathrm{ml}^{-1}$ concanavalin A (Con A; type IV-S; a T cell mitogen), $120 \mu \mathrm{g} \mathrm{ml}^{-1}$ lipopolysaccharide (LPS; E. coli 055:B5; a B cell mitogen), or supplemented RPMI-1640 (unstimulated wells) in triplicate. Plates were incubated for $96 \mathrm{~h}$ at $37^{\circ} \mathrm{C}$ and $5 \% \mathrm{CO}_{2}$, followed by addition of $0.5 \mu \mathrm{Ci}$ of tritiated thymidine per well. After $16 \mathrm{~h}$, cells were harvested and analyzed using a Packard Top Count ${ }^{\mathrm{TM}}-\mathrm{NXT}$ scintillation counter (Packard).

\section{NK cell activity}

NK cell activity was assessed via an in vitro cytotoxicity assay using ${ }^{51} \mathrm{Cr}$-labeled Yac-1 cells as described previously with slight modifications (PedenAdams et al. 2007, Bossart et al. 2008, Reif et al. 2009). PBLs $\left(1 \times 10^{7}\right.$ nucleated cells $\left.\mathrm{ml}^{-1}\right)$ and ${ }^{51} \mathrm{Cr}$-labeled Yac-1 cells were prepared, in triplicate, in ratios of 100:1, 50:1, and 25:1. After a $6 \mathrm{~h}$ incubation at $37^{\circ} \mathrm{C}$ and $5 \% \mathrm{CO}_{2}$, the plates were centrifuged $\left(377 \times g_{i} 5 \mathrm{~min}\right)$, and $25 \mu \mathrm{l}$ of supernate was then 
transferred to a 96-well plate containing solid scintillant (LumaPlate ${ }^{\mathrm{TM}}$ ). Plates were air dried overnight, and then counted for 5 min, after a 10 min dark delay, on the Packard Top Count ${ }^{\mathrm{TM}}-\mathrm{NXT}$ (Packard).

\section{Antibody titers against marine bacteria}

As an indication of a general humoral response to common marine bacteria, specific antibody titers against select marine bacteria were determined in an ELISA system as described previously (Beck \& Rice 2003, Bossart et al. 2008). Cultures of the following bacteria were obtained from the American Type Culture Collection (ATCC; Manassas, VA, USA) and cultured in their recommended broths: Escherichia coli, Erysipelothrix rhusiopathiae, Mycobacterium marinum, Vibrio cholerae, V. carchariae, V. vulnificus, and $V$. parahemolyticus. Calculations of serum antibody titers from individual dolphins following ELISAs were then expressed in terms of antibody titers at a 1:200 serum dilution (Karsten \& Rice 2004).

\section{Study design and statistical analyses}

For purposes of this study, 63 animals were selected from 122 individual IRL dolphins sampled during HERA between 2003 and 2007 using a casecontrol approach. Affected dolphins $(\mathrm{n}=14)$ were defined as those with a positive antibody titer to a CMV. A healthy control group $(\mathrm{n}=49)$ was selected from seronegative animals after eliminating those with definite or probable evidence of disease based on clinicopathologic parameters (Reif et al. 2008). Dolphins with lacaziasis and orogenital papillomas were excluded from the healthy control group because of the previously documented perturbations in immune function associated with these diseases (Bossart et al. 2008, Reif et al. 2009).

All analyses were done using PASW version 18 (SPSS). Descriptive statistics including mean and standard deviation were determined for animals with antibodies to DMV and PMV, and healthy controls. Mean ages of the groups were compared with a $t$-test. The distribution of gender was compared by chi-square analysis. Differences between groups for clinical and immunologic parameters were initially compared using univariate analysis of variance after determining that the data were normally distributed by the Kolmogorov-Smirnov test. The Mann-Whitney $U$-test was used to compare the distributions of variables that were not normally distributed. Multivari- able analysis of variance (MANOVA) was then conducted including age as a covariate. A p-value of $<0.05$ was considered statistically significant.

\section{RESULTS}

Fourteen IRL dolphins were found to be seropositive to a CMV on initial capture between 2003 and 2007, as reported previously (Bossart et al. 2010). Seven dolphins were positive for DMV, 3 for PMV and 4 had antibodies to both DMV and PMV during the observation period. Two dolphins seroconverted between 2006 and 2007 with titers of 1:8 to DMV. Information regarding the health status of the seropositive animals was published previously (Bossart et al. 2010). The mean age of seropositive dolphins $(10.5 \pm 4.6 \mathrm{yr})$ was not significantly different from seronegative dolphins $(11.3 \pm 4.8 \mathrm{yr}, \mathrm{p}=0.69)$. The proportion of males and females was similar between groups (64\% and $57 \%$ for seropositive and seronegative dolphins, respectively, $\mathrm{p}=0.61$ ). Positive titers to DMV ranged from 1:8 to 1:64, while those to PMV ranged from 1:8 to 1:128. Among the 4 dolphins seropositive to both morbilliviruses, titers were higher to DMV than to PMV in 3 dolphins and of equal magnitude in the fourth. The highest titer found was 1:128 against PMV in a dolphin negative for antibody to DMV.

Hematology and serum chemistry results for dolphins with positive morbillivirus antibody titers were similar to those of healthy dolphins. Statistically significant changes were found for only 3 variables (Fig. 1). Serum alkaline phosphatase, creatine phosphokinase and chloride were significantly lower in dolphins with positive morbillivirus titers compared with healthy dolphins. No significant differences were found in the remaining hematological and serum chemistry results.

Differences in immunologic data are summarized in Figs. 2 \& 3. T lymphocyte Con A proliferation was significantly lower in dolphins with positive morbillivirus titers compared to healthy dolphins. Con A stimulation of $\mathrm{T}$ lymphocytes was reduced to approximately $55 \%$ of the healthy value $(\mathrm{p}=0.01)$. Additionally, a marginally significant decrease $(p=0.08)$ in absolute numbers of CD4+ lymphocytes and a marginally significant increase in monocytic phagocytosis ( $p=0.08$ ) were found. Lysozyme concentration was significantly higher $(\mathrm{p}=0.03)$ in dolphins with positive morbillivirus titers compared to healthy dolphins. Dolphins with positive morbillivirus titers had no significant differences in ELISA antibody 

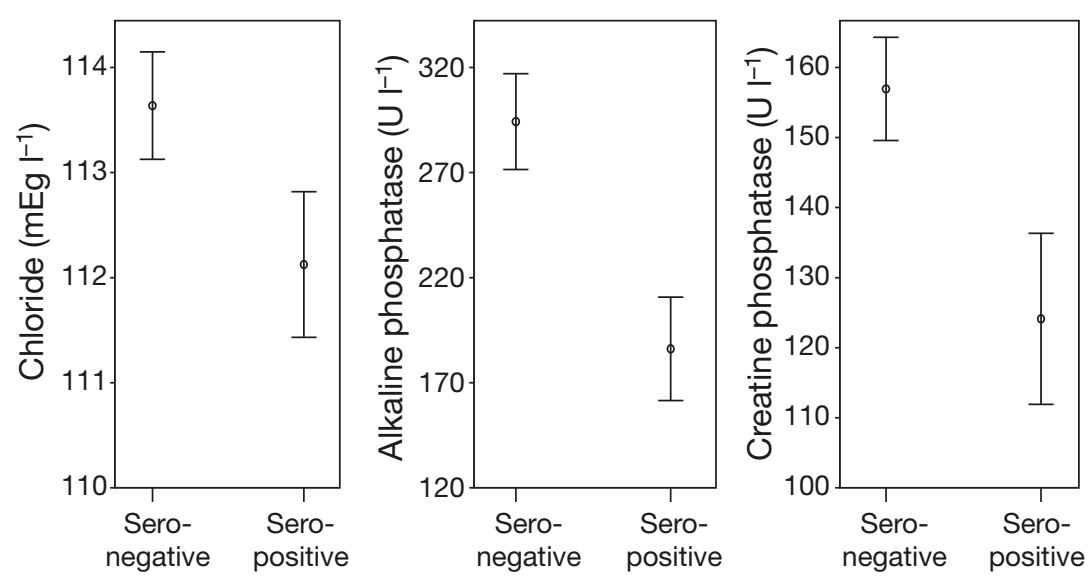

initial examination and 2 additional dolphins developed genital papillomas coincident with seroconversion to CMV or subsequent to it.

\section{DISCUSSION}

Several important clinicoimmunopathologic differences between dolphins with positive CMV antibody titers and healthy seronegative dolphins were found, which suggests that subclinical CMV infection in IRL dolphins may produce perturbations that impact overall health. Statistically significant differences were found for 4 serum chemistry variables. Notably, serum alkaline phosphatase (SAP) was

titers to E. coli, Erysipelothrix rhusiopathiae, Мycobacterium marinum, Vibrio cholerae, V. carchariae, $V$. vulnificus, and $V$. parahemolyticus as compared with healthy dolphins.

Statistically significant serum protein electrophoresis data are shown in Fig. 4. Albumin and albumin: globulin ratios were significantly lower and gamma globulins significantly higher in dolphins with positive morbillivirus titers compared with healthy dolphins.

Histologically confirmed lobomycosis was diagnosed in 2 of the 14 seropositive dolphins. Two seropositive dolphins had genital sessile papillomas on significantly lower in dolphins with positive morbillivirus titers compared with healthy dolphins. SAP levels in bottlenose dolphins vary with age, nutritional status and presence of infection or inflammation (Bossart et al. 2001). SAP levels are used as a nonspecific but important prognostic indicator of the general state of health (Fothergill et al. 1991). Rapid decreases in SAP in dolphins are frequently indicative of a disease state and can be observed with various infectious diseases including lobomycosis (Bossart et al. 2003, Reif et al. 2006). The pathologic mechanism producing decreased SAP levels in dolphins with disease is unknown but it is postulated to
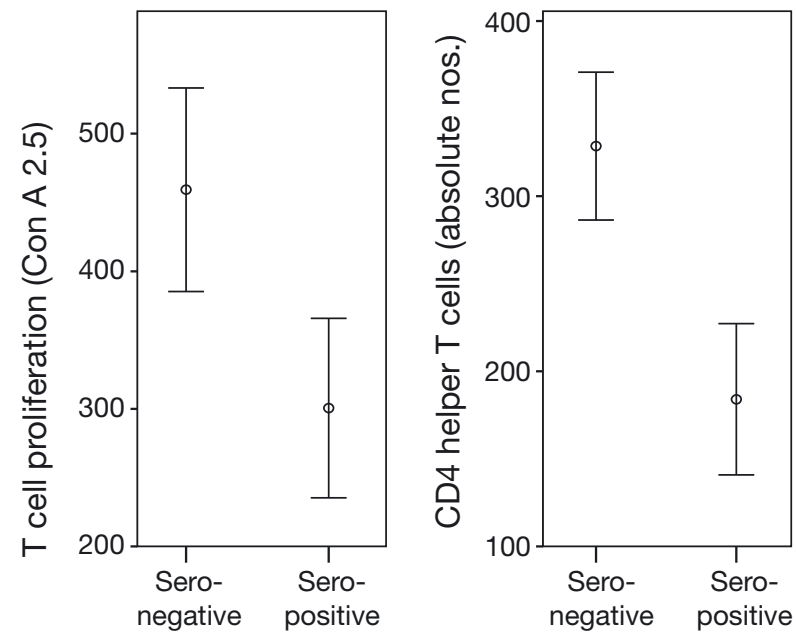

Fig. 2. Tursiops truncatus. Mean ( \pm standard error) $\mathrm{T}$ cell proliferation $(p<0.05)$ and absolute numbers of CD4+ helper T cells $(p=0.08)$ in Atlantic bottlenose dolphins seronegative and seropositive for cetacean morbilliviruses
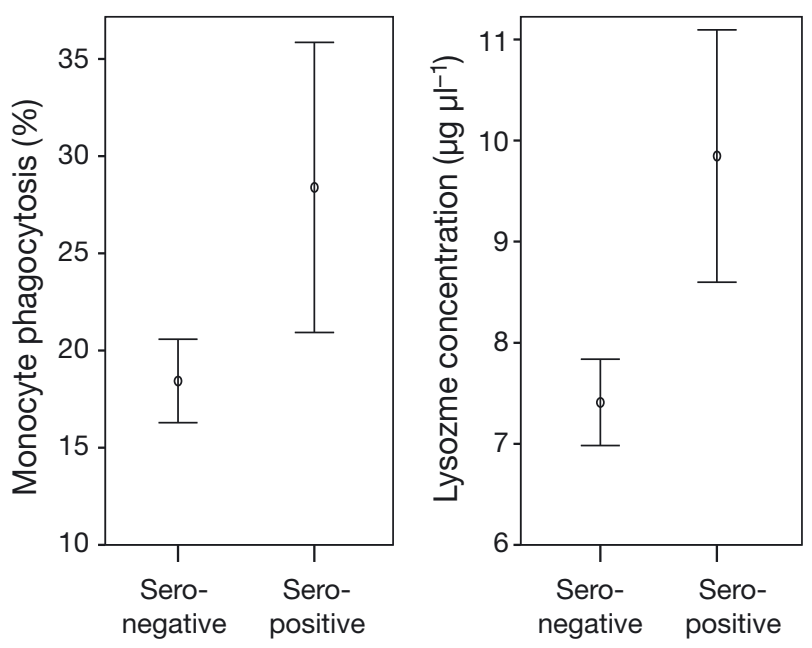

Fig. 3. Tursiops truncatus. Mean ( \pm standard error) monocyte phagocytosis $(\mathrm{p}=0.08)$ and lysozyme concentration $(\mathrm{p}=$ 0.03 ) in Atlantic bottlenose dolphins seronegative and seropositive for cetacean morbilliviruses 

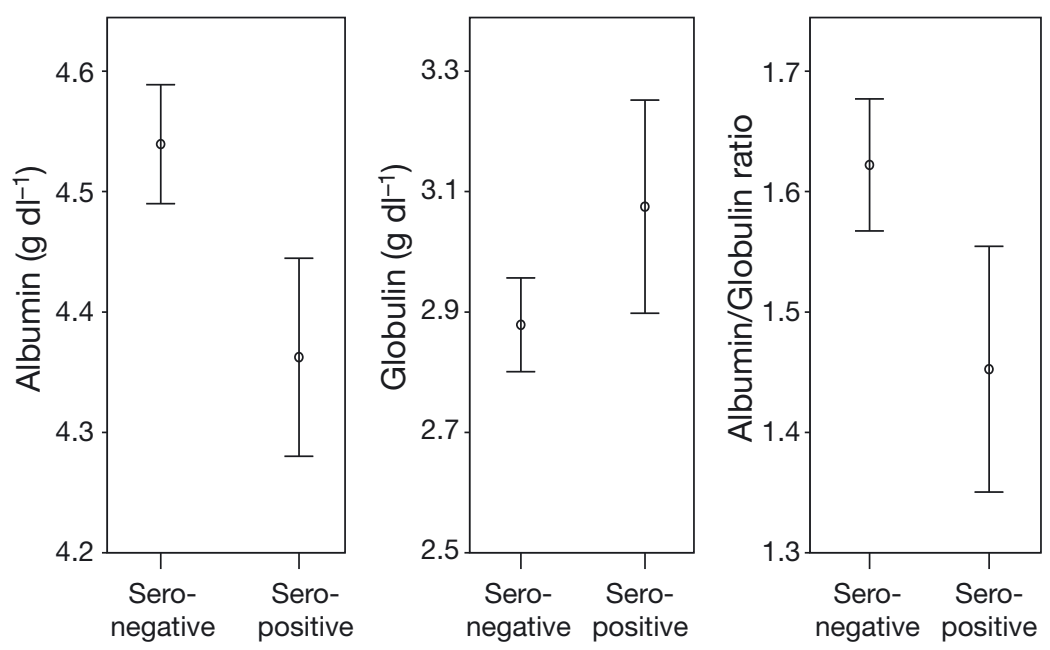

ported higher lysozyme concentrations in HERA dolphins with lobomycosis compared to healthy dolphins (Reif et al. 2009). The significance of elevated lysozyme concentrations in dolphins with positive morbillivirus titers is unknown but suggests upregulation of innate immunity and a pro-inflammatory response to acute CMV infection. In addition, a marginally significant increase was found for monocytic phagocytosis, suggesting upregulation of this cell population. Monocyte upregulation occurs in human MV infection with interaction of MV RNA at the monocyte cell surface, which can trigger signaling pathways and alter cytokine production (Griffin 2010). Further studies are required to determine if the innate immunologic findings are due to sub-

be associated with the ability of SAP to act in endotoxin detoxification, as observed in rats and humans (Bossart et al. 2001, Poelstra et al. 1997). Acute disease with associated endotoxemia may consume and deplete available serum SAP, and so, with resolution of disease, circulating levels of SAP return to normal. Another possible cause for low SAP is related to a negative nutritional status and since inanition may be a clinical component of many dolphin diseases, this alternate mechanism may account for decreases of SAP in this species (Bossart et al. 2001). The low SAP levels in dolphins with positive CMV antibody titers may be due to CMV infection, inanition and/or other concurrent infectious or inflammatory processes and requires further investigation.

Creatine phosphokinase, chloride, and albumin (determined by serum protein electrophoresis) were also significantly lower in dolphins with positive morbillivirus titers. However, the mean values for dolphins with positive morbillivirus titers and healthy dolphins were within the range for healthy dolphins from the same population determined in a previous study (Goldstein et al. 2006). Thus, the findings for these markers are probably not clinically significant.

With respect to innate immunity, no evidence of impaired granulocytic phagocytosis or NK cell activity was present. However, plasma lysozyme concentrations, a marker for pro-inflammatory responses with antibacterial functions, were significantly elevated in dolphins with positive morbillivirus titers $(p=0.03)$. Plasma lysozyme activity has not been extensively studied in dolphins. We recently re- clinical morbillivirus infection which is occurring in this dolphin population (Bossart et al. 2010).

Adaptive immunity was also impacted in dolphins with positive morbillivirus antibody titers. Mitogeninduced $\mathrm{T}$ lymphocyte proliferation responses were significantly reduced in dolphins with positive morbillivirus titers and marginally significant decreases were also found for absolute numbers of CD4+ lymphocytes, suggesting impairment of cell-mediated adaptive immunity. Similar immunologic changes have been reported in the early phase of morbillivirus infection in other mammals. Natural infections of MV, CDV and RPV share common features in the acute phase of disease including lymphopenia, a prolonged cytokine imbalance consistent with suppression of cellular immunity leading to secondary infections and decreased in vitro proliferation of $\mathrm{T}$ cells in response to mitogens (von Messling et al. 2003, Heaney et al. 2005, Kerdiles et al. 2006, Yanagi et al. 2006, Griffin 2007, 2010, Nielsen et al. 2009, Schneider-Schaulies \& Schneider-Schaulies 2009, Avota et al. 2010, Koga et al. 2010). The specific ability of some morbilliviruses to impair T cell-dependent immune responses noted more than 100 yr ago continues to be central to the severe generalized immunosuppression caused by morbilliviruses (Gassert et al. 2009). Furthermore, suppression of mitogen-induced lymphocyte proliferation can be induced by lymphocyte infection with MV or by lymphocyte exposure to a complex of the surface glycoproteins without infection. In children and monkeys with MV infection, the initial mitogen-induced $\mathrm{T}$ 
lymphocyte proliferation can be improved but not completely restored by supplementation of the cultures with interleukin 2 (IL-2), suggesting that failure to produce IL-2 in response to mitogen stimulation is at least part of the proliferative defect (Griffin 2010). Thus, multiple factors may contribute both to MVinduced immune suppression and to the establishment of protective immunity.

The immunosuppressive consequences of MV, CDV and RPV infection can persist for several weeks in the acute stage of morbillivirus infection, rendering animals and humans highly susceptible to opportunistic diseases (Schobesberger et al. 2005). The recent recognition that MV RNA can persist in peripheral blood mononuclear cells for months after clearance of infection suggests that renewed MV replication in cultured cells may contribute to suppressed lymphocyte proliferation (Griffin 2010). Based on the pathogenic mechanisms described in domestic animal and human morbillivirus infections, the immunosuppressive pattern suggests that the dolphins with positive morbillivirus antibody titers are in an acute phase of infection and/or have renewed viral replication. Alternatively, morbillivirus infection in dolphins may produce longer acting cellmediated immunosuppressive effects.

Two of the 14 seropositive dolphins were confirmed cases of lobomycosis and 4 were found to have genital sessile papillomatosis on initial capture or subsequently (Bossart et al. 2010), suggesting that dolphins with positive morbillivirus antibody titers have perturbations of cell-mediated immunity that may render them prone to opportunistic disease, especially orogenital papillomatosis. Including the 2 recaptured seropositive dolphins that developed orogenital neoplasia yields a prevalence estimate of $28.6 \%$, which is higher than the previously reported prevalence in the IRL (15.3\%) (Bossart et al. 2008). The prevalence of lobomycosis in seropositive dolphins $(14.3 \%)$ was similar to what would be expected based on the previously reported prevalence for the IRL (12.0\%) (Reif et al. 2006).

In contrast, dolphins with positive morbillivirus titers appear to have at least a partially upregulated humoral immune response with significantly higher levels of gamma globulins than healthy dolphins. All other measured parameters for humoral immunity and antibody titers to common marine microorganisms were not significantly different. Therefore, the observed hypergammaglobulinemia may represent an antibody response to morbillivirus infection or to other marine pathogens that were not evaluated.
Despite the clinically important cell-mediated immunosuppression discussed above, another distinctive characteristic of morbillivirus infections in domestic animal and humans that eventually survive and appear to clear the virus is the induction of an efficient and often lifelong humoral and cellular immunity (Appel et al. 1982, Griffin 2007). In domestic species and humans with morbillivirus infection, the initial $\mathrm{T}$ cell response includes $\mathrm{CD} 8+$ and T-helper 1 CD4+ $\mathrm{T}$ cells important for control of infectious virus. As viral RNA persists, there is a shift to a T-helper 2 CD4+ T cell response that likely promotes B cell maturation and durable antibody responses (Griffin 2010). The induction of durable humoral immunity to morbillivirus infection in dolphins requires further study especially in light of the profound impacts this infection has had on marine mammal populations worldwide. We plan on addressing the temporal issues of CMV infection impacting immune function and the possibility of renewed viral replication in future HERA studies. We will follow infected individual dolphins over time examining trends in morbillivirus antibody titers, the presence of blood morbillivirus nucleic acid via polymerase chain reaction and immune function including evaluation of a panel of cytokines. These data may also shed additional light on the immunopathogenesis of morbillivirus infection in this species.

Acknowledgements. This research was conducted under National Marine Fisheries Service Permit No. 998-1678-01 and issued Florida Atlantic University IACUC protocol number A10-13. Dolphin health assessments were a collaborative effort between the Harbor Branch Oceanographic Institution and the National Ocean Service, Center for Coastal Environmental and Biomolecular Research, NOAA. Support was provided by the Florida Protect Wild Dolphins program and the NOAA Fisheries Marine Mammal Health and Stranding Response Program. The authors thank the entire bottlenose dolphin HERA project staff for their efforts in this project. In particular, we recognize W. McFee for analyses of dental enamel to estimate age and E. Murdoch for graphic assistance. This work constitutes contribution \#209 from the Sea Research Foundation.

\section{LITERATURE CITED}

Appel MJ, Shek WR, Summers BA (1982) Lymphocyte mediated immune cytotoxicity in dogs infected with virulent canine distemper virus. Infect Immun 37:592-600

Avota E, Gassert E, Schneider-Schaulies S (2010) Measles virus-induced immunosuppression: from effectors to mechanisms. Med Microbiol Immunol (Berl) 199:227-237

Barrett T, Visser IKG, Mamaev LV, Goatley L, Van Bressem MF, Osterhaus ADME (1993) Dolphin and porpoise morbilliviruses are genetically distinct from phocine distemper virus. Virology 193:1010-1012

> Beck BM, Rice CD (2003) Serum antibody titers against 
select bacterial pathogens in Atlantic bottlenose dolphins, Tursiops truncatus, from Beaufort, NC, USA and Charleston Harbor, Charleston, SC, USA. Mar Environ Res 55:161-179

Blixenkrone-Møller M, Bolt G, Gottschalck E, Kenter M (1994) Comparative analysis of the gene encoding the nucleocapsid protein of dolphin morbillivirus reveals its distant evolutionary relationship to measles virus and ruminant morbilliviruses. J Gen Virol 75:2829-2834

Bossart GD (2011) Marine mammals as sentinel species of ocean and human health. Vet Pathol 48:676-690

Bossart GD, Reiderson T, Dierauf L, Duffield D (2001) Clinical pathology. In: Dierauf L, Gulland F (eds) Marine mammal medicine. CRC Press, Boca Raton, FL, p 383-436

Bossart GD, Meisner R, Varela R, Mazzoil M and others (2003) Pathologic findings in stranded Atlantic bottlenose dolphins (Tursiops truncatus) from the Indian River Lagoon, Florida. Fla Sci 66:226-238

Bossart GD, Goldstein JD, Murdoch EM, Fair PA, McCulloch S (2006) Health assessment of bottlenose dolphins in the Indian River Lagoon, Florida and Charleston, South Carolina. Harbor Branch Oceanographic Technical Report No. 93, Ft. Pierce, FL

Bossart GD, Romano TA, Peden-Adams MM, Rice CD and others (2008) Hematological, biochemical and immunological findings in Atlantic bottlenose dolphins (Tursiops truncatus) with orogenital papillomas. Aquat Mamm 34:166-177

Bossart GD, Reif JS, Schaefer AM, Goldstein J, Fair PA, Saliki JT (2010) Morbillivirus infection in free-ranging Atlantic bottlenose dolphins (Tursiops truncatus) from the southeastern United States: Seroepidemiologic and pathologic evidence of subclinical infection. Vet Microbiol 143:160-166

Demers NE, Bayne CJ (1997) The immediate effects of stress on hormones and plasma lysozyme in rainbow trout. Dev Comp Immunol 21:363-373

> Di Guardo G (2008) Dolphin morbillivirus in the Mediterranean Sea. Aquat Mamm 34:514-515

> Di Guardo G, Marruchella G, Agrimi U, Kennedy S (2005) Morbillivirus infections in aquatic mammals: a brief overview. J Vet Med A Physiol Pathol Clin Med 52:88-93

Fair PA, Adams JD, Zolman E, McCulloch S and others (2006) Protocols for conducting dolphin capture release health assessment studies. NOAA NOS NCCOS, Technical Memorandum No. 49, Charleston, SC

- Flaminio MJBF, Rush BR, Davis EG, Hennessy K, Shuman W, Wilkerson MJ (2002) Simultaneous flow cytometric analysis of phagocytosis and oxidative burst activity in equine leukocytes. Vet Res Commun 26:85-92

Fothergill MB, Schwegman CA, Garratt PA, Govender A, Roberston W (1991) Serum alkaline phosphatasechanges in relation to state of health and age of dolphins. Aquat Mamm 17:71-75

- Gassert E, Avota E, Harms H, Krohne G, Gulbins E, Schneider-Schaulies S (2009) Induction of membrane ceramides: novel strategy to interfere with $\mathrm{T}$ lymphocyte cytoskeletal reorganisation in viral immunosuppression. PLoS Pathog 5:e1000623

> Goldstein JD, Reese E, Reif JS, Varela R and others (2006) Hematologic, biochemical and cytologic findings in apparently healthy bottlenose dolphins (Tursiops truncatus) inhabiting the Indian River Lagoon, Florida, USA. J Wildl Dis 42:447-454
Griffin DE (2007) Measles virus. In: Knipe D, Howley P, Griffin D, Lamb R, Martin M, Roizman B, Straus S (eds): Fields virology, 5th edn. Lippincott Williams \& Wilkins, Philadelphia, PA

Griffin DE (2010) Measles virus-induced suppression of immune responses. Immunol Rev 236:176-189

> Heaney J, Cosby SL, Barrett T (2005) Inhibition of host peripheral blood mononuclear cell proliferation ex vivo by rinderpest virus. J Gen Virol 86:3349-3355

> Hohn A, Scott M, Wells R, Sweeney JC, Irvine AB (1989) Growth layers in teeth from free-ranging, known-age bottlenose dolphins. Mar Mamm Sci 5:315-342

Karsten AH, Rice CD (2004) C-reactive protein levels as a biomarker of inflammation and stress in the Atlantic sharpnose shark (Rhizoprionodon terraenovae) from three southeastern USA estuaries. Mar Environ Res 58: 747-751

Keller JM, McClellan PD, Kucklick JR, Keil DE, PedenAdams MM (2006) Effects of organochlorine contaminants on loggerhead sea turtle immunity: comparison of a correlative field study and in vitro exposure experiments. Environ Health Perspect 114:70-76

> Kennedy S (1998) Morbillivirus infections in aquatic mammals. J Comp Pathol 119:201-225

> Kerdiles YM, Sellin CI, Druelle J, Horvat B (2006) Immunosuppression caused by measles virus: role of viral proteins. Rev Med Virol 16:49-63

> Koga R, Ohno S, Ikegame S, Yanagi Y (2010) Measles virusinduced immunosuppression in SLAM knock-in mice. J Virol 84:5360-5367

Lehmann AK, Sørnes S, Halstensen A (2000) Phagocytosis: measurement by flow cytometry. J Immunol Methods 243:229-242

Mazzoil M, Reif JS, Youngbluth M, Murdoch ME and others (2008) Home ranges of bottlenose dolphins (Tursiops truncatus) in the Indian River Lagoon, Florida: environmental correlates and implications for the management strategies. EcoHealth 5:278-288

Nielsen L, Søgaard M, Jensen TH, Andersen MK, Aasted B, Blixenkrone-Møller M (2009) Lymphotropism and host responses during acute wild-type canine distemper virus infections in a highly susceptible natural host. J Gen Virol 90:2157-2165

Peden-Adams MM, EuDaly JG, Dabra S, EuDaly A, Heesemann L, Smythe J, Keil DE (2007) Suppression of humoral immunity following exposure to the perfluorinated insecticide sulfluramid. J Toxicol Environ Health A 70:1130-1141

Peden-Adams MM, Romano T (2005) Development and standardization of a suite of assays to assess immunotoxicity in the bottlenose dolphin. In: Fair PA, Bossart GD (eds), Synopsis of researcher meeting-bottlenose dolphin health assessment project. NOAA NOS NCCOS Technical Memorandum No. 10, Charleston, SC

> Poelstra K, Bakker WW, Klok PA, Hardonk MJ, Meijer DKF (1997) A physiologic function for alkaline phosphatase: endotoxin detoxification. Lab Invest 76:319-327

> Reif JS, Mazzoil M, McCulloch SD, Varela RA, Goldstein JD, Fair PA, Bossart GD (2006) Lobomycosis in Atlantic bottlenose dolphins (Tursiops truncatus) from the Indian River Lagoon, Florida. J Am Vet Med Assoc 228: 104-108

Reif JS, Fair PA, Adams J, Joseph B and others (2008) Evaluation and comparison of the health status of Atlantic bottlenose dolphins from the Indian River Lagoon, 
Florida and Charleston, South Carolina. J Am Vet Med Assoc 233:299-307

Reif JS, Peden-Adams MM, Romano TA, Rice CD, Fair PA, Bossart GD (2009) Immune dysfunction in Atlantic bottlenose dolphins (Tursiops truncatus) with lobomycosis. Med Mycol 47:125-135

Romano TA, Keogh MJ, Kelly C, Feng P and others (2004) Anthropogenic sound and marine mammal health: Measures of the nervous and immune systems before and after intense sound exposure. Can J Fish Aquat Sci 61: 1124-1134

Saliki JT, Lehenbauer TW (2001) Monoclonal antibodybased competitive enzyme-linked immunosorbent assay for detection of morbillivirus antibody in marine mammal sera. J Clin Microbiol 39:1877-1881

Schneider-Schaulies S, Schneider-Schaulies J (2009) Measles virus induced immunosuppression. Curr Top Microbiol Immunol 330:243-269

Editorial responsibility: Michael Moore, Woods Hole, Massachusetts, USA
Schobesberger M, Artur S, Doherr M, Zurbriggen A, Griot C (2005) Canine distemper virus-induced depletion of uninfected lymphocytes is associated with apoptosis. Vet Immunol Immunopathol 104:33-44

- Van Bressem MF, Raga JA, Di Guardo G, Jepson PD and others (2009) Emerging infectious diseases in cetaceans worldwide and the possible role of environmental stressors. Dis Aquat Organ 86:143-157

Visser IKG, Van Bressem MF, de Swart RL, van de Bildt MWG and others (1993) Characterization of morbilliviruses isolated from dolphins and porpoises in Europe. J Gen Virol 74:631-641

von Messling V, Springfeld C, Devaux P, Cattaneo R (2003) A ferret model of canine distemper virus virulence and immunosuppression. J Virol 77:12579-12591

Yanagi Y, Takeda M, Ohno S (2006) Measles virus: cellular receptors, tropism and pathogenesis. J Gen Virol 87: 2767-2779

Submitted: May 23, 2011; Accepted: September 2, 2011 Proofs received from author(s): November 23, 2011 